\title{
Tricks that relieve camptocormia during gait in Parkinson's disease patients
}

\author{
Truques que melhoram a camptocormia durante a marcha em doentes com Doença de Parkinson
}

\author{
Cristina Semedo 1 , Ana Calado², Margarida Dias ${ }^{3}$, Manuel Almeida ${ }^{4}$, \\ Rui Pedrosa
}

\begin{abstract}
Introduction. Camptocormia is an extreme flexion of the toracolumbar spine that exacerbates by walking and is relieved in the supine position. It is described with increasing frequency in association with Parkinson disease (PD). Its pathogenesis remains unclear. One of the hypotheses proposed defends that when associated with PD probably it is a focal action dystonia of the paraspinal muscles. Dystonia may be accompanied of a "geste antagoniste". It is a kind of trick that enables the patient to alleviate dystonic posture. We present two cases in which the patients use sensory tricks to alleviate their posture during gait. Case Reports. Patient 1: A 74-year-old woman, with a 2-year of PD. Clinical examination disclosed parkinsonian signs and camptocormia. She was able to partially overcome it by pushing her hands against her thighs. Patient 2: A 80-year-old woman, with a 1-year probable PD. Neurological examination revealed postural instability, freezing gait and camptocormia that partially remits when she pushes a bar at the level of her waist. Conclusions. The particularity of these cases is that patients are able to improve camptocormia during gait by specific tricks. This clinical improvement supports the hypothesis that camptocormia in PD is a focal dystonia of the paraspinal muscles.
\end{abstract}

Keywords. Parkinson disease, Posture, Distonic Disorders.

Citation. Semedo C, Calado A, Dias M, Almeida M, Pedrosa R. Tricks that relieve camptocormia during gait in Parkinson's disease patients.

\section{RESUMO}

Introduçáo. A Camptocormia é a flexão extrema da coluna dorsolombar que agrava durante a marcha e remite em supinação. Tem sido descrita frequentemente associada à Doença de Parkinson (DP). A sua patogenia não se encontra ainda esclarecida. Uma das hipóteses propostas defende que quando associada à DP se trata provavelmente de uma distonia de acção focal dos músculos paraespinhais. A distonia pode ser acompanhada do "geste antagoniste", que consiste num truque que permite ao doente aliviar a postura distónica. Apresentamos dois casos em que os doentes utilizam truques para aliviar a sua postura durante a marcha. Casos Clínicos. Doente 1: Mulher de 74 anos, com diagnóstico de DP há 2 anos. No exame neurológico apresentava parkinsonismo e camptocormia, que melhorava parcialmente ao apoiar as mãos nas suas coxas. Doente 2: Mulher de 80 anos com o diagnóstico de DP provável há 1 ano. No exame neurológico apresentava instabilidade postural, bloqueios da marcha e camptocormia que remitia parcialmente quando segurava uma barra à altura da cintura. Conclusóes. A particularidade destes casos clínicos consiste no facto de os doentes melhorarem a camptocormia durante a marcha através de truques. Esta melhoria clínica suporta a hipótese de a camptocormia na DP ser um distonia focal dos músculos paraespinhais.

Unitermos. Doença de Parkinson, Postura, Distúrbios Distónicos.

Citação. Semedo C, Calado A, Dias M, Almeida M, Pedrosa R. Truques que melhoram a camptocormia durante a marcha em doentes com Doença de Parkinson.
Study performed at Department of Neurology, Hospital de Santo António dos Capuchos, Centro Hospitalar de Lisboa Central, E.P.E.

1. Resident of Neurology, MD.

2. Neurologist, MD.

3. Neurologist, MD.

4. Neurologist, MD.

5. Neurologist, MD, Head of the Department of Neurology, Centro Hospita-

lar de Lisboa Central.
Endereço para correspondência: Cristina Semedo

Department of Neurology, Hospital de Santo António dos Capuchos, Centro Hospitalar de Lisboa Central, E.P.E.,

Lisboa, Portugal

Phone: +351965307921

Fax: +351213136344

E-mail: crissemedo@gmail.com

Relato de Caso Recebido em: 29/04/11

Aceito em: 09/08/11

Conflito de interesses: não 


\section{INTRODUCTION}

Camptocormia is defined as an abnormal flexion of the trunk that appears when standing or walking and disappears when in the supine position.

The condition was described by Earle in 1815 and by Brodie in 1837, but the term itself was introduced by Souques to describe the forward flexion posture of some soldiers in World War I who had to bend to move through the trenches to avoid injury ${ }^{1-3}$. The word is derived from the Greek words "kamptos" to bend and "kormos" trunk.

Despite considered evidence of a conversion disorder in earlier cases, camptocormia has been linked to a variety of organic diseases in the past decade, including parkinsonism, primary and secondary dystonias, spinal deformities, neuromuscular disorders, psychogenic causes, and others ${ }^{4}$.

Initially considered a rare feature of Parkinson's disease (PD), a prevalence of $6.9 \%$ was reported by Tiple and co-workers ${ }^{5}$. It is associated with greater discomfort and disability ${ }^{6}$.

The mechanism of pathogenesis in PD remains unclear and several hypothesis have been put forward. One of them postulates that it is probably a central disorder, considering camptocormia as a focal action dystonia of the paraspinal muscles resulting from an excessive activation of the abdominal wall muscles ${ }^{4}$.
Dystonia is defined by involuntary, sustained contractions of muscles, leading to sustained abnormal postures or movements ${ }^{7}$. One of the most distinctive features of focal dystonias is their frequent improvement with sensory tricks (or geste antagoniste). It is a kind of trick or manoeuvre that enables the patient to alleviate the dystonic posture. These often involve tactile stimulation of a particular body part, most often with mild force. The pathophysiology of this phenomenon has not been elucidated so far. One of the most postulated hypotheses suggests that it influences propioceptive "input".

We present two case reports of patients with PD according to the UK Brain Bank Criteria that use a "geste antagoniste" to improve posture during gait ${ }^{9}$.

\section{Patients' reports}

\section{Ref: $16 / 2011$}

Case 1: This 74-year-old woman presented a 2-year history of progressive gait difficulty and stooped posture. Upon examination she had hypomimia, bradykinesia and rigidity more pronounced on the right side of the body. Her gait was notable for its slow shuffling step and anteroflexion of the trunk with backward extension of the head (Fig. 1). The patient's arm swing was diminished bilaterally and more pronounced on the right side. There was complete resolution of her camptocormia in supine.

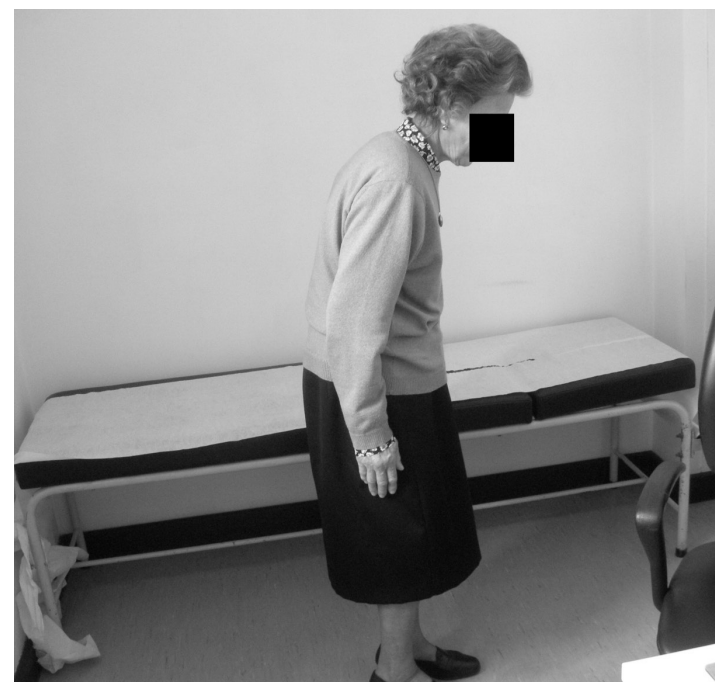

Figure $1 \mathrm{~A}$

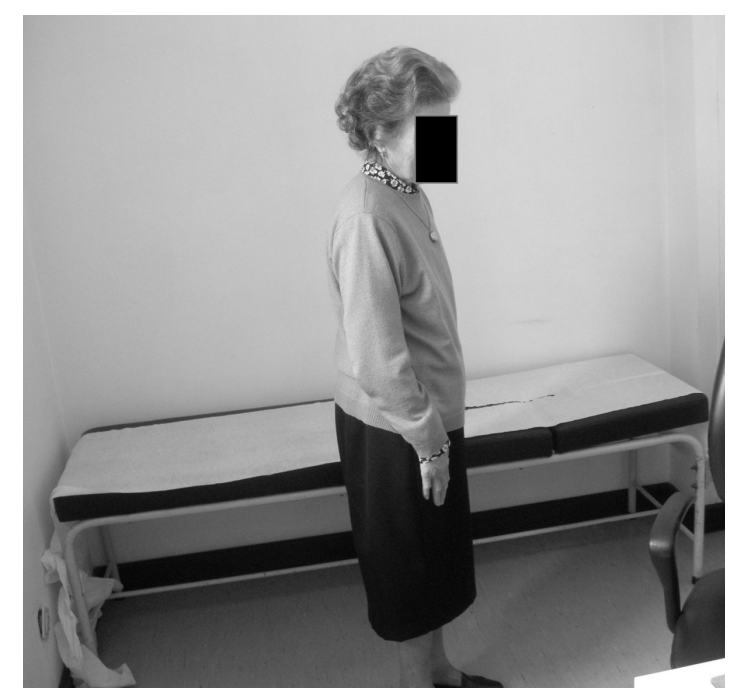

Figure 1B

Figure 1. Case 1. Camptocormia in a 74-year-old patient with Parkinson's disease (A). Her posture is markedly improved when she pushes her hands against her thighs (B). Patient consent has been received to publish this figure.

Patient consent has been received to publish this figure 
Non-demented, without frontal release signs, extra ocular movements were normal. No weakness or wasting of paraspinal muscles. Neuroimaging revealed chronic microvascular leukoencephalopathy. DaTSCAN showed a symmetric reduction of tracer uptake with more marked loss in putamen. At the time of presentation the patient was on Carbidopa-Levodopa (CD-LD) 25-100mg 3 times a day and selegiline $5 \mathrm{mg} 2$ times a day, without significant improvement. It was supplemented with entacapone and selegiline. On her own initiative, she interrupted medication for two weeks resulting in worsening camptocormia. Higher dosis of dopaminergic therapy was not tolerated. She was able to partially overcome the camptocormia during gait by pushing her hands against her thighs. This manoeuvre allowed her to straighten her back while walking (Fig. 2).

Case 2: This 80-year-old woman presented a 1 -year postural instability, freezing gait and incapability to walk straight. She reported lower back pain. Upon examination she exhibited bradykinesia, marked flexion of the spine and lateral side deviation to her left side. She had no difficulty in lying down flat in supine position. No paraspinal muscle paresis or wasting. She was able to partially overcome her camptocormia by holding a bar at waist level, like when pushing a shopping trolley. She was progressively placed on a high dose of levodopa (CB-
LD 25/100 up to 6 times a day plus CB-LD 50-200 sustained-release) which resulted in a marked improvement of parkinsonian symptoms but no change in her posture. Neuroimaging revealed a small cortical, left temporal infarction, and chronic microvascular leukoencephalopathy. Cervical MRI demonstrated multilevel osteoarticular degenerative disease.

\section{DISCUSSION}

Although camptocormia is receiving more attention, its pathogenesis and consequently its treatment still need to be determined. Three mechanisms have been considered as probable aetiology for camptocormia: dystonia, rigidity, and myopathy.

The more attractive hypothesis to consider for our two PD patients (case 1 and 2) is to consider camptocormia as a segmental dystonia of the trunk. The abnormal flexion of the trunk that appears when standing or walking and disappears in supine position could be caused by an excessive activation of the abdominal wall muscles ${ }^{10}$. The improvement of flexed posture the patients achieved with the sensory tricks previously described also supports camptocormia as a form of dystonia. Our patients could even improve posture during gait (when it usually gets worse) using a sensory trick. The fact that patients use sensory tricks to improve their posture has already been

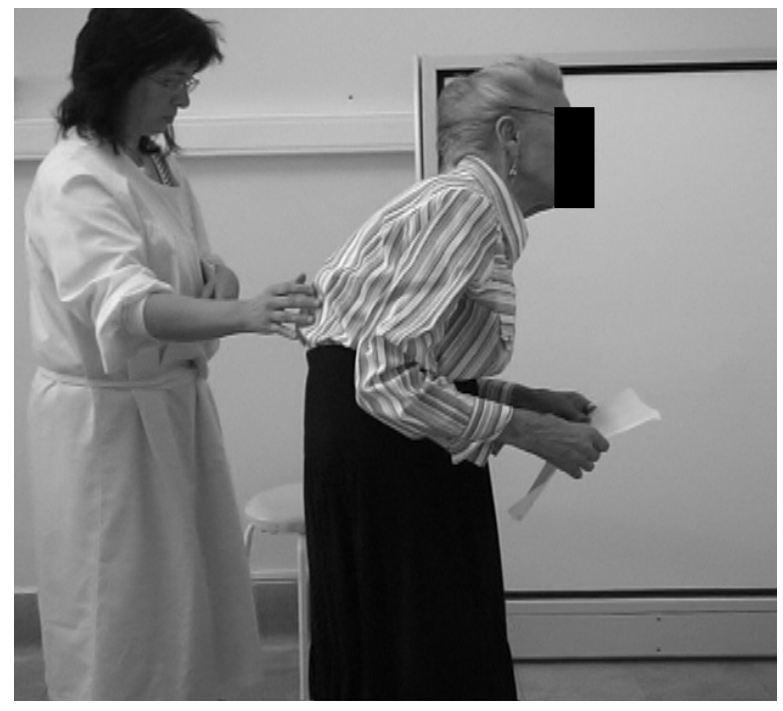

Figure $2 \mathrm{~A}$

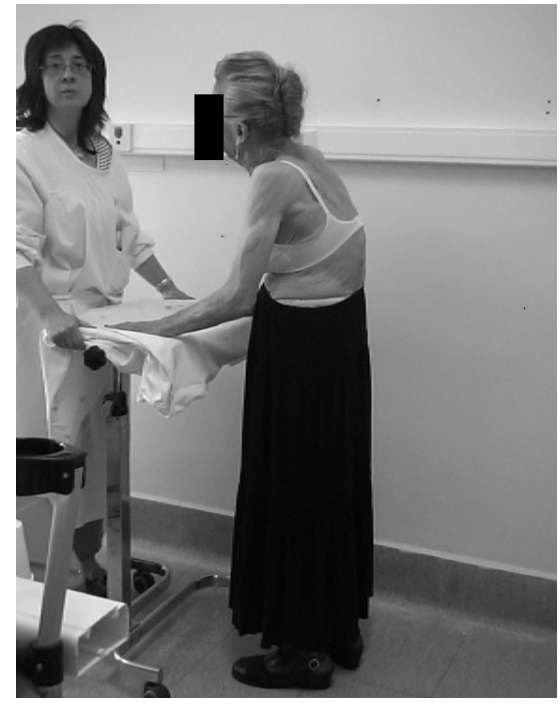

Figure 2B

Figure 2. Case 2. Photographs of an 80-year-old woman with camptocormia (A) that is markedly improved when she to partially overcome her camptocormia by holding a bar at waist level (B).

Patient consent has been received to publish this figure 
reported in literature ${ }^{4,11}$. The past history of spondyloarthrotic vertebral changes could be considered as a peripheral trauma acting as a trigger for dystonia.

It is theoretically possible that camptocormia in $\mathrm{PD}$ is the result of specific nigroputaminal dopaminergic projections, but the lack of correlation between the degree of camptocormia and clinical and treatment-related variables could imply that the patophysiology of camptocormia involves additional non-dopaminergic mechanisms. The role of dopaminergic therapy on this disorder is complex. There are a few anecdotal reports of camptocormia that respond to dopaminergic treatment, botulinum toxin and deep brain stimulation ${ }^{4-12}$.

Furthermore, another hypothesis for explaining parkinsonian camptocormia is the axial rigidity of flexion muscles, with weakness of the erector spinal muscles pointed out as a possible cause of camptocormia in PD patients ${ }^{13}$. This would be a consequence of dysfunction of the basal ganglia controlling the reticulospinal pathway. It is unlikely that camptocormia could be a result of paraspinal rigidity in our patients otherwise it would not remit in supine position.

Currently, the discussion remains, especially since Margraf and co-workers published their study where they concluded that the most likely parkinsonian camptocormia is a focal myopathy of the paravertebral muscles ${ }^{14}$. On the other hand, the possibility of an over-use myopathy has been mentioned by some researchers ${ }^{13,15}$. We did not find any axial weakness in our patients and, for this reason, no further studies were performed to evaluate an eventual myopathic disorder.

\section{CONCLUSIONS}

In summary, we support the theory that considers camptocormia in PD patients a form of focal action dystonia, considering that the most important finding of our two cases was the clinical demonstration of the use of a sensory trick to improve patients' posture during gait. The relevance of determining the mechanism behind camptocormia consists in its implication on the therapeutic approach of this disabling condition.

\section{REFERENCES}

1.Earle H. Reply to the review of Mr Bayton's essay on the cure of crooked spine. Edinburg Med Surg J 1815;11:35-51.

2.Brodie BC. Pathological and surgical observations on the disease of the joints. In: Longman, Hurst, Rees, Orme, Brown, eds. London 1818;1822:376. Reprinted by the Classic of Medicine Library, Birmingham, Alabama, USA 1989. 3.Souques A, Rosanoff-Saloff A. La camptocormie; incurvation du tronc, consecutive aux traumatismes du dos et des lombes; considerations morphologiques. Rev Neurol 1914-1915;28:937-9.

4.Azher SN, Jankovic J. Camptocormia: pathogenesis, classification, and response to therapy. Neurology, 2005;65:355-9.

http://dx.doi.org/10.1212/01.wnl.0000171857.09079.9f

5.Tiple D, FabbriniG, Colosimo C, Ottaviani D, Camerota F, Defazio G, et al. Camptocormia in Parkinson's disease: an epidemiological and clinical study. J Neurol Neurosurg Psychiatry 2009;80:140-8.

http://dx.doi.org/10.1136/jnnp.2008.150011

6.Bloch F, Houeto JL, Tezenas du Montcel S Bonneville F, Etchepare F, Welter M-L, et al. Parkinsons disease with camptocormia. J Neurol Neurosurg Psychiatry 2006;77:1223-8.

http://dx.doi.org/10.1136/jnnp.2006.087908

7.Fahn S, Marsden CD, Calne DB, Classification and investigation of dystonia. In Marsden CD Fahn S, ed Movement disorders 2. London: Butterworth, 1987 , p.332-58.

8.Fahn S. Concept and classification of dystonia. Adv Neurol 1988;50:1-8. 9.UKPDBB- Hughes AJ Daniel SE, Kilford L, Lees AJ. Accuracy of clinical diagnosis of idiopathic Parkinson's disease: a clinico-pathological study of 100 cases. J Neurol Neurosurg Psychiatry 1992;55:181-4.

http://dx.doi.org/10.1136/jnnp.55.3.181

10.Djaldetti R, Mosberg-Galili R, Sroka H, Merims D, Melamed E. Camptocormia (bent spine) in patients with Parkinson's disease: characterization and possible pathogenesis of an unusual phenomenon. Mov Disord 1999;14:443-7. http://dx.doi.org/10.1002/1531-8257(199905)14:3<443::AIDMDS1009>3.0.CO;2-G

11.Gerton BK, Theeler B, Samii A. Backpack treatment for camptocormia. Mov Disord 2010;30:247-8.

http://dx.doi.org/10.1002/mds.22909

12.Melamed E, Djaldetti R. Camptocormia in Parkinson's disease. J Neurol 2006; 253(suppl 7):VII/14-16.

13.Lepoutre A C, Devos D, Blanchard-Dauphin A, Pardessus V, Maurage C-A, Ferriby D, et al. A specific clinical pattern of camptocormia in Parkinson's disease. J Neurol Neurosurg Psychiatry 2006;77:1229-34.

http://dx.doi.org/10.1136/jnnp.2005.083998

14.Margraf NG, Wrede A Rohr A, Schulz-Schaeffer WJ, Raethjen J, Eymess

A. Camptocormia in idiopathic Parkinson's disease: A focal myopathy of the paravertebral muscles. Mov Disord 2010;25:542-51.

http://dx.doi.org/10.1002/mds.22780

15.Bonneville F, Bloch F, Kurys E, Tezenas du Montcel S, Welter M-L, Bommet A-M, et al. Camptocormia and Parkinson's disease: MR imaging. Eur Radiol 2008;18:1710-9.

http://dx.doi.org/10.1007/s00330-008-0927-8 